\title{
Forecasting the Twelve Month Treasury Bill Rates in Sri Lanka: Box Jenkins Approach
}

\author{
D.M.K.N. Seneviratna ${ }^{1}$, Mao Shuhua ${ }^{2}$ \\ $\left({ }^{1}\right.$ School of Economics, Wuhan University of Technology, Wuhan, P.R. China, 430070. ${ }^{1}$ Department of \\ Interdisciplinary Studies, Faculty of Engineering, University of Ruhuna, Sri Lanka) \\ $\left({ }^{2}\right.$ Department of Statistics, School of Sciences, Wuhan University of Technology, Wuhan, P.R. China, 430070)
}

\begin{abstract}
In this study, univariate time series Autoregressive Integrated Moving Average (ARIMA) model is used to forecast government twelve month Treasury bill rates in Sri Lanka over the period June, 2008 to June, 2013. Box Jenkins methodology is mainly used to build four models and different diagnostic tests and criteria were applied to select the appropriate model. The accuracy of the forecasted values is compared with Mean Squared Error (MSE) and Mean Absolute Error (MAE). The empirical results reveal that the best ARIMA model for the twelve month treasury bill rates is ARIMA $(1,1,2)$. The obtained model was used to forecast next five weeks period and the results showed that the slow decay of the T-bill rates. The decreasing of the interest rates implies that the increasing the considerable demand for the government T-bills. Therefore the findings of this study have been given some impression to the investors for planning their future investments.
\end{abstract}

Keywords - ARIMA models, Box Jenkins, Forecasting, Treasury bill rates

\section{INTRODUCTION}

The Financial market is a place where issues the securities to the public. Basically there are two types of government securities namely Treasury Bills and Treasury Bonds. Among them, Treasury bills can be known as short term, highly marketable, liquid and low-risk debt securities. Moreover, T-bills make a functional relation between the public and the government. Generally, government raises their necessary capital requirements by selling their bills to the public. On the other hand public gives their contribution through investing on bills. The maturity periods of T-bills are different. They are varying weekly such as 4, 13, 26 and 52. The public can purchase T-bills directly from the treasury or auction and the secondary market as well as can be sold at any time in the secondary market after purchasing [8]. Though the risky situation always incorporates with securities while investing, T-bills are categorized as low risk assets compared to the others since they are issued under the government authority. Due to these reasons the government T-bills are highly marketable than the other investments.

Normally the public can purchase T-bills with a discount through a competitive bidding process. Discounts represents the interest, which would be different based on the maturity. This interest will increase when the prices go down and will decrease when the prices rise. The fluctuation of the T-bill rates is affected by several factors such as supply and demand of T-bills, inflation, economic conditions and monetary policy. Normally there is a significant demand for government T-bills due to the short term period and low risk assets. When the demand for T-bills goes up, the government reduces the discount since the number of available investors are high. The government drops a supply of T-bills when there is a budget surplus in the country. As well as T-bill rates go up due to the poor investment conditions would arise during the period of inflation. On the other hand T-bill rates go up and down when the country is in a recession and boom respectively. Therefore the volatility of the interest or discounts of T-bills is a very important condition for both the public and the government to understand the economic behavior of the country.

People are more interested in investing their capitals in government T-bills rather than the other securities. Attentive on interest rates and low risk assets can be considered as significant factors for increasing investments.Therefore if it is possible to give an impression about the volatility of the T-bill rates, it will help to investors as well as the stability of the country's economy. Hence the main objective of this study is to find an appropriate Autoregressive Integrated Moving Average (ARIMA) model to forecast government T-bill rates. For this purpose government twelve month treasury bill rates (by week) in Sri Lanka are considered over the period from June, 2008 to June 2013. Secondary data are obtained through the published data from Central bank of Sri Lanka.

The next part of the study is organized as follows. Section II gives the background of the literature based on ARIMA model. Methodology explains in section III. The empirical results are given in section IV. Section V presents the conclusion of this study. 


\section{LITERATURE REVIEW}

Different type of methodologies have been developed to overcome this problem. Among them, many researchers used ARIMA models for forecasting results. In 2013, Paul et al used ARIMA model for forecasting average daily share price index of pharmaceutical companies in Bangladesh. In their study, they found the best fitted ARIMA model after considering the different type of factors such as Akaike Information, corrected Akaike information, Schwartz information, mean absolute percent error, root mean square error and absolute mean error. Their empirical results indicated that the ARIMA $(2,1,2)$ model is the best for forecasting the average daily share price indices [1].

Chujai et al conducted a research to find a model for forecasting the electricity consumption in a household. As a main objective of their study, the most suitable forecasting method was fitted. The analysis results suggested that, two forecasting methods called autoregressive integrated moving average and autoregressive moving average (ARMA) are most suitable for forecasting future results. For this purpose they applied Box Jenkins method and identified the best suitable model is ARIMA for monthly and quarterly as forecasting periods. On the other hand, they showed that the ARMA model is suitable for forecasting based on daily and weekly periods [2].

Inflation rate in Nigeria was forecasted by Olajide et al based on the Box Jenkins approach. Yearly data from 1961 to 2010 was used. According to the empirical results, they suggested that the ARIMA $(1,1,1)$ model is the most adequate for the inflation rate. Based on the suggested model, they predicted the inflation rate at $16.27 \%$ in the year 2010 [3].

Kumar et al presented a study to build a univariate time series model to forecast the exports of industrial goods from Punjab. They followed the Box Jenkins methodology and used several criteria to check the validity of the model. Finally they observed that the ARIMA $(2, d, 1)$ is the optimal for forecasting the variable exports [4].

According to the literature, another study carried out by Chen et al (2008) based on ARIMA model. They used this model to forecast short-term property crime for one city of China. In this study they compared ARIMA model with other two exponential smoothing models and showed that the best fit is given by ARIMA model [5].

Al-Sahib studied the predictability of the Amman Stock Exchange(ASE) based on ARIMA model over a period of seven days. Different diagnostic tests used to perform the best fitted model and showed that the selected model is suitable for forecasting on ASE [6]. Another research based on ARIMA model has done by Nochai et al. They investigated to find a model to forecast three types of oil palm price in Thailand such as Farm price, Wholesale price and Pure oil price. Non-seasonal Box Jenkins methodology is used and three models are found based on the minimum of mean absolute percentage error (MAPE). Finally they developed model for three types of palm oil price and found that models ARIMA $(2,1,0)$ for the farm price, ARIMA $(1,0,1)$ for the wholesale price, and ARIMA $(3,0,0)$ for the pure oil price [7].

\section{DATA \& METHODOlOGY}

The study is carried out based on weekly data of Twelve month Treasury bill rates as secondary data, which have been collected from Central Bank of Sri Lanka, over the period from June, 2008 to June 2013.

The object of this study is to find the appropriate ARIMA model to forecast twelve month treasury bill rates in Sri Lanka. For this purpose non-seasonal Box Jenkins approach is used to find the best fitted ARIMA model and the accuracy of the forecasting values are checked by comparing residuals. The steps of the suggested model and its forecasting can be explained in the following steps.

Determining whether the time series is stationary or not is a very important concept before making any inferences in time series analysis. Therefore Augmented Dickey Fuller (ADF) and Phillips-Person (PP) tests has been used to check the stationarity of the data series.

There are several methods can be applied to fit a time series model. Among them, Autoregressive Integrated moving average (ARIMA) model is used on the stationary data in this study.

\subsection{Autoregressive Integrated Moving Average (ARIMA) Model}

ARIMA models are extensions of an ARMA process by the integrated (I) part and can be obtained by combining the $\mathrm{AR}(\mathrm{p})$ and $\mathrm{MA}(\mathrm{q})$ models and defined in (1).

$$
\phi(B) \nabla^{d} Y_{t}=\phi(B)(1-B)^{d} Y_{t}=\theta(B) Z_{t},\left\{Z_{t}\right\} \sim W N\left(0, \sigma^{2}\right)
$$

Where $\mathrm{p}$ and $\mathrm{q}$ are orders of $\mathrm{AR}$ and MA models, $\phi(B)$ and $\theta(B)$ are polynomials of order $\mathrm{p}$ and $\mathrm{q}$ respectively. d, non negative integer is the number of differences. $B$ is the backward shift operator [9]. Estimating an ARIMA model was first approached by Box and Jenkins (1976) and according to their methodology, it follows three steps as Identification, Estimation, and Diagnostic Checking [10]. The three steps can be summarized in the following sections. 


\subsection{Model Identification : Box Jenkins Approach}

Model identification is the determination of the order of the model, basically which can identify based on sample autocorrelation (ACF) and sample partial autocorrelation (PACF) plots [10]. The Table 1 explained the way of determining the ARIMA model using sample ACF and sample PACF [9].

Table 1: Properties of the ACF and PACF of AR, MA and ARMA Series

\begin{tabular}{|l|c|c|}
\hline \multicolumn{1}{|c|}{ Model } & ACF & PACF \\
\hline AR $(p)$ & Tails off & Cut off after lag $p$ \\
\hline MA (q) & Cut off after lag $q$ & Tails off \\
\hline ARMA $(p, q)$ & Tails off & Tails off \\
\hline
\end{tabular}

\subsection{Estimation of the Model Parameters}

After identifying the possible ARIMA models, the maximum likelihood method is used to estimate the model parameters [10].

\subsection{Diagnostic Checking}

The next step is to select the best model among all the identified models. For this, residual diagnostics and information criteria as AICC and BIC were used to check the adequacy. Under the residual diagnostics, Ljung-Box Q statistic is used to check whether the residuals are random or not [10]. The corresponding null and alternative hypothesis can be written as follows.

$H_{0}$ : The model does not exhibit lack of fit

$H_{1}$ : The model exhibits lack of fit

The test statistic $Q$ is displayed in (2).

$Q=n(n+2) \sum_{k=1}^{m} \frac{\hat{r}_{k}^{2}}{n-k}$

; where $\hat{r}_{k}$ is the estimated autocorrelation of the series at lag $k, m$ is the number of lags includes in the test, and $n$ is the number of residuals. The conclusion is considered based on the p-value associated with the $Q$ statistic. If p-value $<\alpha$, then it implies the adequacy of the model [11].

Moreover corrected Akaike's and Bayesian information criteria can be used to select the suitable model which has the lowest AICC and BIC values. On the other hand ACF and PACF plots of residuals can be used to check the randomness of the residuals.

\subsection{Forecasting}

Finally, Forecasting is done for all the selected models and calculated mean squared error (MSE) and mean absolute error (MAE) for all the models. The most accurate forecasting among the models is selected by considering the lowest value of the MSE and MAE [10]. Then the best fitted value has been used to forecast twelve month treasury bill rates for the next Five weeks.

\subsection{Stationarity}

\section{RESULTS AND DISCUSSION}

As a first step, behavioral analysis was carried out based on Time series plot and ACF plot. Time series plot of Fig.1 shows that, nonexistence of significant trend and seasonal components of data in our experiment period. The ACF plot of Fig.1 shows the strong and slowly decaying autocorrelations. Moreover, it implies that the non stationarity of the level data.
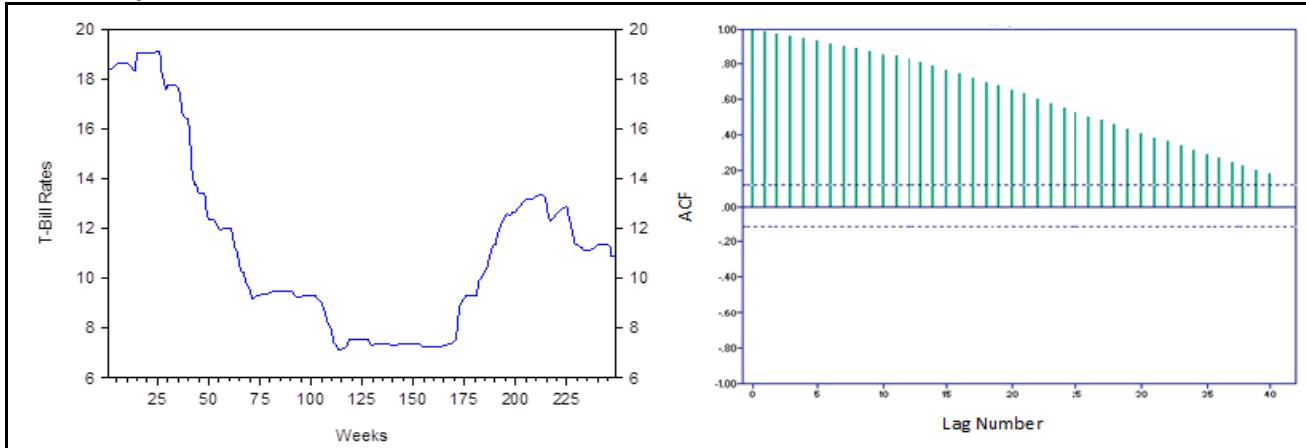

Figure 1: time series plot and ACF plot of data (by week) 
Fig.2 shows the sample ACF and PACF of the first difference series. Clearly, it shows that the significant autocorrelation at lag 1 and others are not significant. It suggests that the first difference series is stationary.
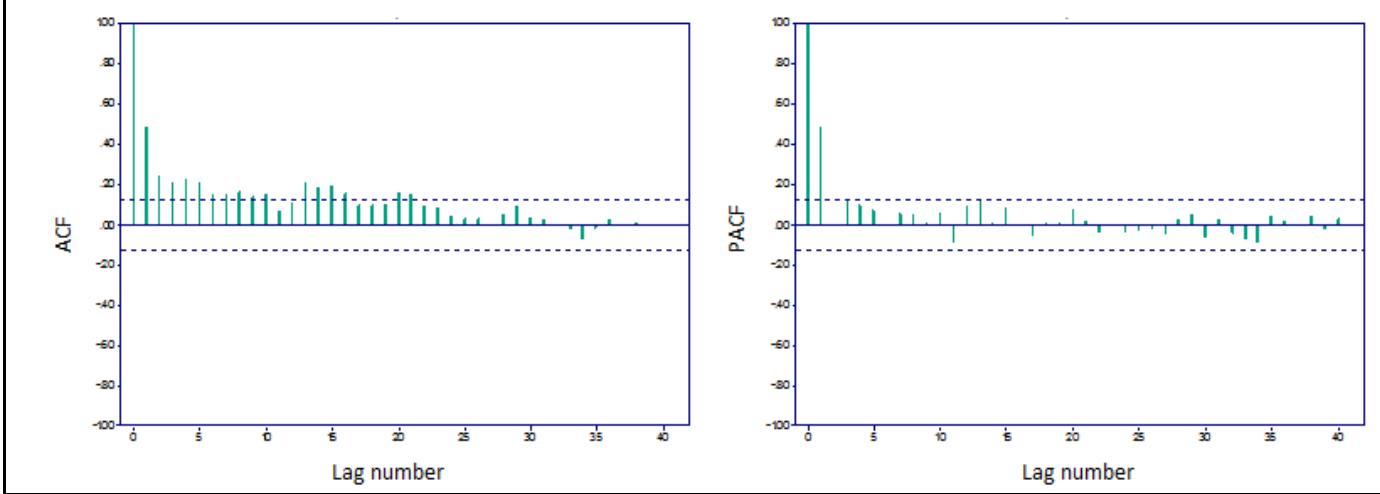

Figure 2: Sample ACF and PACF of the First difference series

Table 2: Unit root test results

\begin{tabular}{|l|c|c|}
\hline \multicolumn{1}{|c|}{ Test } & Level & First Difference \\
\hline ADF & $-2.030886(0.2735)$ & $-9.188496(0.0000)$ \\
\hline PP & $-1.968550(0.3007)$ & $-9.332742(0.0000)$ \\
\hline
\end{tabular}

The ADF and PP test results show that the series is non stationary at levels and stationary at the first difference. The results coincide with the Time series plot, ACF plots and unit root results. So, results suggested that the series is stationary at the first difference.

\subsection{Model Identification}

According to the plots and unit root tests results, level data are not stationary and the series is stationary at the first difference. Therefore ARIMA model can be proposed for the first difference series. Based on the ACF and PACF plots in Fig.2, it shows that the autocorrelation of the first lag in the two plots is significant. Therefore Four possible models can be suggested for the difference series. They are ARIMA $(1,1,0)$, ARIMA $(0,1,1)$, ARIMA $(0,1,2)$ and $\operatorname{ARIMA}(1,1,2)$.

\subsection{Model Estimation}

In this study Maximum likelihood method is used to estimate the model parameters and the results are displayed in Table 3.

Table 3: Estimated model parameters

\begin{tabular}{|c|c|c|}
\hline Model & Coefficients & S.E \\
\hline ARIMA(1,1,0) & 0.485360 & 0.0342246 \\
\hline ARIMA(0,1,1) & 0.441615 & 0.0356097 \\
\hline ARIMA(0,1,2) & 0.485904 (for MA(1)) & 0.0347496 \\
& 0.149540 (for MA(2)) & 0.0329417 \\
\hline ARMA(1,1,2) & 0.946450 (for AR(1)) & \\
& -0.502120 (for MA(1)) & \\
& -0.296288 (for MA(2)) & \\
\hline
\end{tabular}

(6).

According to the maximum likelihood estimation, Four models can be explained in (3), (4), (5), and

ARIMA $(1,1,0)$

$\Delta Y_{t}=0.485360 \Delta Y_{t-1}+Z_{t}$ or $Y_{t}=Y_{t-1}+0.485360\left(Y_{t-1}-Y_{t-2}\right)+Z_{t}$

ARIMA $(0,1,1)$

$\Delta Y_{t}=Z_{t}+0.441615 Z_{t-1}$ or $Y_{t}=Y_{t-1}+Z_{t}+0.441615 Z_{t-1}$

ARIMA $(0,1,2)$

$\Delta Y_{t}=Z_{t}+0.485904 Z_{t-1}+0.149540 Z_{t-2}$ or

$Y_{t}=Y_{t-1}+Z_{t}+0.485904 Z_{t-1}+0.149540 Z_{t-2}$

ARIMA $(1,1,2)$ 


$$
\begin{aligned}
& \Delta Y_{t}=0.946450 \Delta Y_{t-1}+Z_{t}-0.502120 Z_{t-1}-0.296288 Z_{t-2} \quad \text { or } \\
& Y_{t}=Y_{t-1}+0.946450\left(Y_{t-1}-Y_{t-2}\right)+Z_{t}-0.502120 Z_{t-1}-0.296288 Z_{t-2}
\end{aligned}
$$

\subsection{Model Selection} in Table 4.

The values for AICC, BIC, Ljung-Box statistic, and probability of the selected Four models are given

Table 4: Comparative results of models

\begin{tabular}{|c|c|c|c|c|}
\hline Model & AICC & BIC & $\begin{array}{c}\text { Ljung-Box } \\
\text { Statistic }\end{array}$ & P-value \\
\hline ARMA $(1,1,0)$ & $-0.128842 \mathrm{E}+03$ & $-0.127814 \mathrm{E}+03$ & 28.506 & 0.09794 \\
\hline ARMA $(0,1,1)$ & $-0.119055 \mathrm{E}+03$ & $-0.118154 \mathrm{E}+03$ & 65.003 & 0.0000 \\
\hline ARMA $(0,1,2)$ & $-0.123044 \mathrm{E}+03$ & $-0.120215 \mathrm{E}+03$ & 43.743 & 0.00163 \\
\hline ARMA $(1,1,2)$ & $-0.134008 \mathrm{E}+03$ & $-0.129451 \mathrm{E}+03$ & 13.979 & 0.83158 \\
\hline
\end{tabular}

Compared with all the results in Table 4, the minimum values for both AICC and BIC are indicated to the ARIMA $(1,1,2)$ model. As well as the minimum standard error is also given by the same model. On the other hand, the null hypothesis do not reject at the 0.05 level of significance of the ARIMA $(1,1,2)$ model based on the Ljung-Box statistic. By comparing all these test values in Table 4, it can be suggested that the ARIMA $(1,1,2)$ is the most appropriate model for representing the Twelve month treasury bill rates.

\subsection{Model Forecasting}

Since the accuracy of the forecasting values is measured by comparing the mean square error (MSE) and mean absolute error (MAE), residuals are obtained for all the proposed ARIMA models. Then the MSE and MAE are calculated and displayed in Table 5.

Table 5: Forecasting results of the selected models

\begin{tabular}{|c|c|c|}
\hline \multicolumn{1}{|c|}{ Model } & MSE & MAE \\
\hline ARIMA $(1,1,0)$ & 0.0342237 & 0.0971311 \\
\hline ARIMA $(0,1,1)$ & 0.0356096 & 0.102205 \\
\hline ARIMA $(0,1,2)$ & 0.0347493 & 0.0995121 \\
\hline ARIMA $(1,1,2)$ & 0.0342216 & 0.0970514 \\
\hline
\end{tabular}

The minimum values for MSE and MAE are given under the model ARIMA $(1,1,2)$, it suggests that the accurate forecasting values can be obtained using the ARIMA $(1,1,2)$ model. Then the forecasting values are shown in Fig. 3 and Table 6.

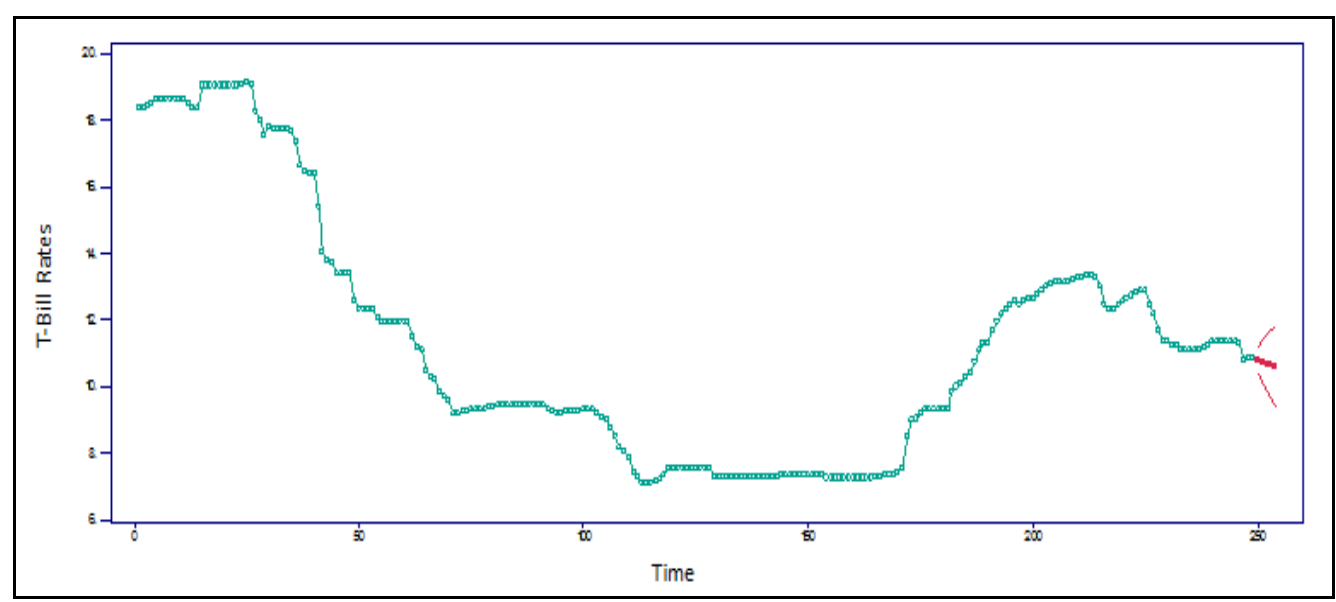

Figure 3: Weekly Time Series Forecasting for Treasury Bill Rates (twelve month)

The forecasted values for next five weeks from June 2013 for twelve month T-bill rates are shown in Table 6. 
Table 6: Forecasted twelve months T-bill rates since June, 2013

\begin{tabular}{|c|c|c|c|c|}
\hline Step & Prediction & Sqrt (MSE) & \multicolumn{2}{|c|}{$\begin{array}{c}\text { Approximate 95 Percent } \\
\text { Prediction Bounds }\end{array}$} \\
\cline { 4 - 5 } & & & Lower & Upper \\
\hline 1 & 10.80512 & 0.18150 & 10.44939 & 11.16085 \\
\hline 2 & 10.75995 & 0.31884 & 10.13502 & 11.38487 \\
\hline 3 & 10.71557 & 0.42745 & 9.87778 & 11.55335 \\
\hline 4 & 10.67193 & 0.52571 & 9.64155 & 11.70231 \\
\hline 5 & 10.62901 & 0.61871 & 9.41635 & 11.84166 \\
\hline
\end{tabular}

The forecasting results suggested that, there will be a slow decreasing of the twelve month treasury bill rates in the next five weeks.

\section{CONCLUSION}

This study was carried out to find an appropriate ARIMA model to forecast Twelve month government T-bill rates in Sri Lanka. For this purpose Box Jenkins methodology was used and ARIMA $(1,1,2)$ model was selected as the most suitable model based on MSE and MAE. ARIMA $(1,1,2)$ forecasting model used to forecast the next five weeks T-bill rates and it does not show significant volatility. However, there is a very slow decay can be seen. Therefore mainly investors can plan their future investments by considering the future behavior of the $\mathrm{T}$ bill rates. On the other hand decreasing of the interest rates implies that the increasing the considerable demand for the government T-bills.

\section{REFERENCES}

[1] J.C. Paul, S. Hoque, and M.M. Rahman, Selection of Best ARIMA Model for Forecasting Average Daily Share Price Index of Pharmaceutical Companies in Bangladesh: A case Study on Square Pharmaceutical Ltd, Global Journal of Management and Business Research, 13(3), 2013.

[2] P. Chujai, N. Kerdprasop, and K. Kerdprasop, Time Series Analysis of Household Electric Consumption with ARIMA and ARMA Models, Proc. IMECS Conf., Hong Kong, 2013.

[3] J.T. Olajide, O.A. Ayansola, M.T. Odusina, and I.F. Oyenuga, Forecasting the Inflation Rate in Nigeria: Box Jenkins Approach, IOSR Journal of Mathematics (IOSR-JM), 3(5), 2012, 15-19.

[4] G. Kumar, and S. Gupta, Forecasting Exports of Industrial Goods from Punjab - An Application of Univariate ARIMA Model, Annals of the University of Petrosani, 10(4), 2010,169-180.

[5] P. Chen, H. Yuan, and X. Shu, Forecasting Crime Using the ARIMA Model, 5th IEEE Conf. on Fuzzy Systems and Knowledge Discovery, 2008.

[6] M. Al-Shiab, The Predictability of the Amman Stock Exchange using the Univariate Autoregressive Integrated Moving Average (ARIMA) Model, Journal of Economic \& Administrative Sciences, 22(2), 2006.

[7] R. Nochai, and T. Nochai, ARIMA Model for Forecasting Oil Palm Price, Proc. 2nd IMT-GT Regional Conf. on Mathematics, Statistics and Applications, University Sains Malaysia, Penang, 2006.

[8] Z. Bodie, A. Kane, and A.J. Marcus, Investments (Inc and China Machine Press: McGraw-Hill Companies, 2012).

[9] MAS328, Time series analysis (University London: School of Mathematical Sciences, 2006).

[10] C. Brooks, Introductory econometrics or finance (New York, USA: Cambridge University Press, 2008).

[11] G.S. Maddala, Introduction to econometrics (West Sussex, England: John Wiley \& Sons Ltd, 2002). 